\title{
Involvement of Neuropeptide $Y$ in Hyperphagia in Human Growth Hormone Transgenic Rats
}

\author{
Hiroyuki HOZUMI ${ }^{1)}$, Keitaro YAMANOUCHI ${ }^{1)}$ and Masugi NISHIHARA ${ }^{1) *}$ \\ ${ }^{1)}$ Department of Veterinary Physiology, Veterinary Medical Science, The University of Tokyo, 1-1-1 Yayoi, Bunkyo-ku, Tokyo 113-8657, \\ Japan
}

(Received 2 February 2006/Accepted 19 May 2006)

ABSTRACT. We have previously produced human growth hormone (hGH) transgenic (TG) rats that show low circulating levels of both hGH and endogenous rat GH. Although body length of the TG rats is normal, they develop hyperphagia and severe obesity. The present study was undertaken to elucidate the causes of hyperphagia in the TG rats by focusing on temporal changes in plasma ghrelin levels and hypothalamic neuropeptide Y (NPY) contents. In both wild-type (WT) and TG rats, the highest value of plasma ghrelin levels was observed just before the dark phase, and thereafter plasma ghrelin levels were maintained higher in the TG than WT rats. Although NPY contents also showed the peak level just before the dark phase in both the arcuate (ARC) and paraventricular nuclei (PVN) of the hypothalamus, the values in the ARC, but not the PVN, of the TG rats was always lower than those of the WT rats, suggesting increased transport of NPY from the ARC to PVN in the TG rats. In addition, treatment with antagonists for Y1 and Y5 receptors for NPY reduced food intake much more effectively in the TG than WT rats. Intermittent treatment with recombinant hGH for a week significantly decreased food consumption, adipose tissue weight and plasma triglyceride concentrations in the TG rats. These results suggest that, in the TG rats, insufficiency in circulating GH stimulates the ghrelin-NPY system with a resultant increase in food intake.

KEY WORDS: ghrelin, growth hormone, hyperphagia, neuropeptide $\mathrm{Y}$, transgenic rat.

J. Vet. Med. Sci. 68(9): 959-965, 2006

Growth hormone $(\mathrm{GH})$ is secreted from the pituitary gland in a pulsatile manner and plays an important role in regulating metabolism as well as somatic growth $[8,10]$. The actions of GH on metabolism involve both anabolism, such as protein synthesis in the muscle, and catabolism, such as lipolysis in the adipose tissue. Therefore, the role of $\mathrm{GH}$ is very important in terms of maintaining the balance of body composition. Indeed, GH-deficient (GHD) subjects become obesity with short stature and this obesity in GHD subjects is improved by GH-replacement therapy [9, 29]. Since the subjects of Prader-Willi syndrome (PWS), a type of GHD, typically represent hyperphagia [14], GH may also be involved in maintaining normal feeding.

We have previously generated transgenic (TG) rats expressing human $\mathrm{GH}(\mathrm{hGH})$ gene under the control of mouse whey acidic protein promoter [18]. Contrary to our expectation, serum hGH levels in the TG rats were relatively low and endogenous pulsatile secretion of rat GH was eliminated. While their body length was similar to that of the wild-type (WT) rats, the TG rats developed severe obesity [15] and hyperphagia [12], suggesting that they suffered from GHD. Additionally, the TG rats showed several symptoms that are linked to non-insulin dependent diabetes mellitus, e.g. hyperglycemia, hyperinsulinemia, and hypertriglyceridemia [16]. The TG rats, therefore, appear to be a good experimental model for the study of hyperphagia and resulting obesity and metabolic diseases under the condition of GHD.

Recently, ghrelin, a 28 amino acid peptide with n-

\footnotetext{
* Correspondence to: Nishihara, M., Department of Veterinary Physiology, Veterinary Medical Science, The University of Tokyo, 1-1-1 Yayoi, Bunkyo-ku, Tokyo 113-8657, Japan.
}

octanoylation in the 3rd serine residue, was isolated from stomach in humans and rats. Ghrelin was identified as a ligand of GH secretagogue receptor, and shown to stimulate the secretion of GH from the pituitary [24]. Its $n$-octanoylation in the 3rd serine residue was shown to be mandatory for the stimulatory effect on GH secretion. Furthermore, it became clear that ghrelin had a potent orexigenic action [27]. Ghrelin administered peripherally or centrally promoted not only GH secretion but also food consumption and body weight gain [24]. The orexigenic effect of ghrelin is thought to be mediated by hypothalamic peptides such as neuropeptide Y (NPY) and agouti-related protein (AgRP) [27]. NPY is known to be one of the most potent orexigenic factors [13]. NPY-producing neurons are located in the arcuate nucleus (ARC) of the hypothalamus and mainly project their fibers to the paraventricular nucleus (PVN) [2]. Although there are subtypes from Y1 to Y6 in NPY receptors, the $\mathrm{Y} 1$ and $\mathrm{Y} 5$ receptors are regarded to participate in the regulation of food intake [7, 19, 22, 23].

The present study was conducted to elucidate whether the ghrelin-NPY system is involved in hyperphagia in the TG rats with low circulating GH. To this end, diurnal changes in food intake, plasma ghrelin concentrations and NPY contents in the ARC and PVN were simultaneously examined. The effects of antagonists for $\mathrm{Y} 1$ and $\mathrm{Y} 5$ receptors, as well as recombinant $\mathrm{hGH}(\mathrm{rhGH})$, on food intake were also assessed.

\section{MATERIALS AND METHODS}

Animals: Generation of TG rats has been described previously [18]. Throughout the present study, the female TG 
rats (heterozygotes) and their WT littermates were used. They were housed in a room at controlled temperature of $23^{\circ} \mathrm{C}$ with a lighting schedule of $12 \mathrm{hr}$ light/dark (light on at $0700 \mathrm{~h}$ ). After being weaned from mothers at 3 weeks of age, they were individually housed with free access to laboratory chow and water. Body weight was recorded once a week from 4 to 14 weeks of age and food consumption was recorded from 5 to 14 weeks of age ( $n=6$ for each group). At 12 weeks of age, all the WT and TG rats were ovariectomized under ether anesthesia. Two weeks after surgery, food consumptions over $24 \mathrm{hr}$ were recorded every $2 \mathrm{hr}$ ( $\mathrm{n}=6$ for each group), and the animals were further subjected to the experiments described below. All the experiments were conducted according to the Guideline for the Care and Use of Laboratory Animals, the University of Tokyo.

Determination of plasma ghrelin: For the measurements of plasma ghrelin, WT and TG rats ( $\mathrm{n}=5-7$ for each group) were decapitated at 1100, 1500, 1700, 1900 and $2300 \mathrm{hr}$. Blood samples were collected to the tubes containing EDTA $\cdot 2 \mathrm{Na}(1.25 \mathrm{mg} / \mathrm{m} l)$ and aprotinin (Trasylol, Bayer AG, Munich, Germany, $500 \mathrm{U} / \mathrm{m} l$ blood), and centrifuged at $1,800 \times \mathrm{g}$ for $20 \mathrm{~min}$ at $4^{\circ} \mathrm{C}$. After centrifugation, plasma samples were added with $1 \mathrm{~N} \mathrm{HCl}$ (10\% volume) immediately, and stored $-80^{\circ} \mathrm{C}$ until used. Plasma ghrelin concentrations were measured using a commercial active ghrelin ELISA kit (Mitsubishi Kagaku Iatron, Inc., Tokyo, Japan), which did not recognize des-acyl ghrelin, following the manufacturer instructions.

Determination of NPY in the hypothalamus: WT and TG rats were decapitated at 1100, 1500, 1700, 1900 and $2300 \mathrm{hr}$ ( $n=4-6$, for each point), and the hypothalamic regions containing exclusively the ARC and the PVN were dissected out. The tissue samples containing the ARC and PVN were obtained using a brain matrix (RBM-4000c, Activational Systems, Inc., Forterra, MI). With the ventral surface of the brain facing up in the brain matrix that was prechilled on ice, a blade was inserted into a slot of the brain matrix at the place of $4.1 \mathrm{~mm}$ posterior from the bregma. The second blade was inserted into a slot $2 \mathrm{~mm}$ rostral from the first blade, and the third blade was inserted into a slot $1 \mathrm{~mm}$ rostral from the second blade. The tissue block containing the ARC was trimmed approximately $2 \mathrm{~mm}$ square at the ventral part of the third ventricle from the first slice, and the tissue block containing the PVN was trimmed approximately 1 $\mathrm{mm}$ square at the dorsal part of the third ventricle from the second slice. Each of the tissue samples were as homogenized with $0.1 \mathrm{~N} \mathrm{HCl}$ and centrifuged at $18,000 \times \mathrm{g}$ for 30 min at $4^{\circ} \mathrm{C}$, and the supernatants were was collected and stored $-80^{\circ} \mathrm{C}$ until used. Amount of protein of the supernatants was measured by Bradford method (Protein Assay kit, Bio-Rad, Hercules, CA). The NPY assay was performed using commercial NPY RIA kit (Peninsula Laboratories, INC, San Carlos, CA) according to the assay protocol supplied by the manufacturer.

Administration of NPY Y1- and Y5-receptor antagonists: Antagonists for Y1-receptor [22] and Y5-receptor [23] were kindly supplied by Banyu Pharmaceutical Co., Ltd., Japan.
The WT and TG rats ( $\mathrm{n}=6$ for each group) were intraperitonealy (i.p.) administrated with vehicle, 10 and $30 \mathrm{mg} / \mathrm{kg}$ body weight (BW) of antagonists (dissolved in ethanol/ polyethylenglycol 600/saline, 10/25/65) at $1800 \mathrm{hr}$, and the food consumption of the whole dark phase (1900-0700 hr) was measured.

Administration of rhGH: The TG rats $(\mathrm{n}=6)$ were administrated i.p. with rhGH (Novo Nordisk, Bagscaaerd, Denmark) at a dose of $100 \mu \mathrm{g} / \mathrm{rat}$ in $0.3 \mathrm{~m} l$ saline 4 times a day at $4 \mathrm{hr}$ intervals between 0700 and $1900 \mathrm{hr}$ for 7 days as described previously [15]. As a control, WT $(n=6)$ and TG rats $(n=9)$ were administered saline $(0.3 \mathrm{~m} l)$ alone. During the experiment, food consumption was measured daily. Three hour after the last injection $(2,200 \mathrm{hr}$ on day 7$)$, the animals were decapitated and their blood samples were collected. Body weight and the weight of corpus adiposum ovarii (CAO) were recorded, and plasma triglyceride concentrations were measured with commercial kit (Wako, Osaka, Japan).

Statistical analysis: All the data was analyzed by ANOVA followed by Tukey-Kramaerís test as a post-hoc test. Graphed data are expressed as mean \pm SE. P values less then 0.05 were considered as statistically significant.

\section{RESULTS}

Food consumption in TG rats: In the TG rats, body weight (Fig. 1A) and food consumption (Fig. 1B) were significantly larger than those in the WT rats throughout the observation period between 4 and 14 weeks of age. These results were in consistent with our previous results in male rats $[11,15]$. Food consumption of every $2 \mathrm{hr}$ over $24 \mathrm{hr}$ is shown in Fig. 2A. In both WT and TG rats, food consumption evidently increased at the beginning of the dark phase, which was the largest value throughout $24 \mathrm{hr}$, and there was not a significant difference in $2 \mathrm{hr}$ food consumption between WT and TG rats. However, cumulative food consumption during the light phase, dark phase and whole day was significantly increased in the TG rats compared with the WT rats (Fig. 2B).

Plasma ghrelin concentrations: Changes in plasma ghrelin concentrations between 1100 and $2300 \mathrm{hr}$ are shown in Fig. 3. At $1100 \mathrm{hr}$, plasma ghrelin concentration was significantly lower in TG than in WT rats. In both WT and TG rats, the highest value was observed just before the dark phase $(1700 \mathrm{hr})$. Thereafter, plasma ghrelin concentrations were maintained higher in the TG than in WT, and the difference at $1900 \mathrm{hr}$ was significant.

Hypothalamic NPY contents: Changes in NPY contents in brain tissues containing the ARC and PVN between 1100 and $2300 \mathrm{hr}$ are shown in Fig. 4A and B, respectively. In the ARC of WT rats, NPY contents significantly increased at $1700 \mathrm{hr}$ than before, and thereafter the contents declined. Similar changes were observed in NPY contents in the ARC of TG rats, but the values in TG were always lower than those in WT rats. In the PVN, the highest contents of NPY were also observed at $1700 \mathrm{hr}$ in both WT and TG rats, the 
A

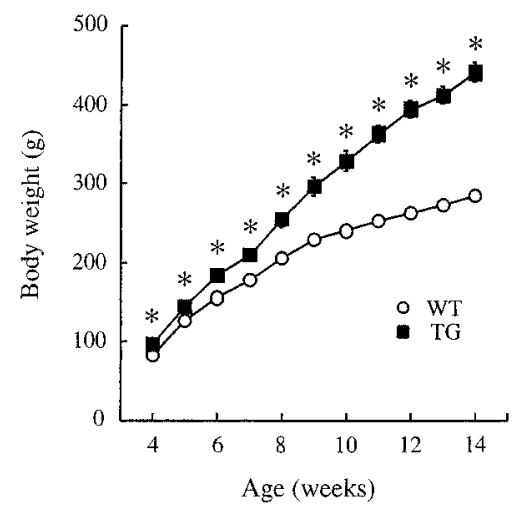

B

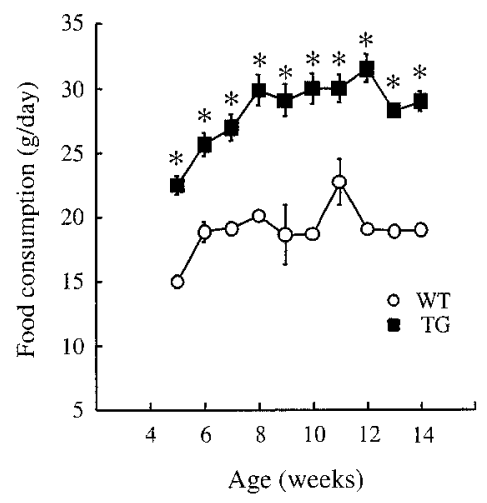

Fig. 1. Changes in body weight (A) and food consumption (B) in the wild-type (WT) and transgenic (TG) rats with age. Each symbol and vertical bar represents mean $\pm \mathrm{SE}$ $(\mathrm{n}=6) .{ }^{*} \mathrm{p}<0.05$ vs. WT.

A

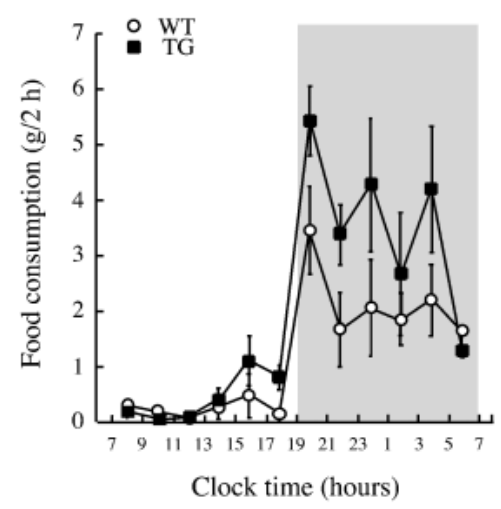

B

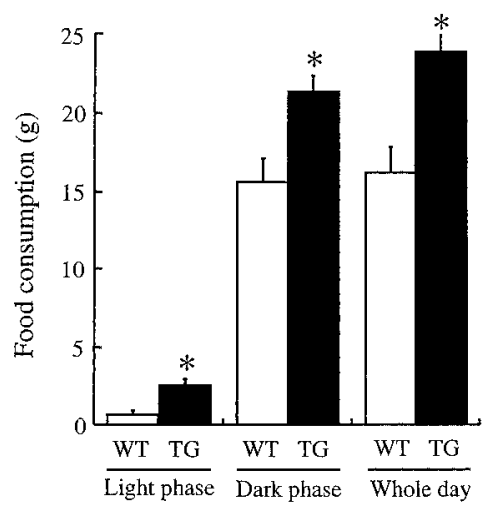

Fig. 2. Food consumption every $2 \mathrm{hr}$ for over $24 \mathrm{hr}$ (A) and that during the light phase, dark phase and whole day (B) in wild-type (WT) and transgenic (TG) rats. Shaded area in (A) shows the dark phase. Each symbol, column and vertical bar represents mean \pm $\mathrm{SE}(\mathrm{n}=6) .{ }^{*} \mathrm{p}<0.05$ vs. WT.

values of which were significantly higher than those at 1100 and $1900 \mathrm{hr}$. There were no significant difference in NPY contents in the PVN between WT and TG rats except at $1700 \mathrm{hr}$, when the content was significantly higher in TG than in WT rats.

Effects of NPY antagonists on food consumption: The effects of Y1 and Y5 antagonists on food consumption of the dark phase are shown in Fig. 5A and B, respectively. In the WT rats, Y1 antagonist at a dose of $30 \mathrm{mg} / \mathrm{BW}$ significantly decreased food consumption, though that of $10 \mathrm{mg} /$ BW did not affect food consumption. In the TG rats, Y1 antagonists at doses of 10 and $30 \mathrm{mg} / \mathrm{BW}$ significantly suppressed food consumption in a dose-dependent manner. On the other hand, Y5 antagonist at all the doses used did not affect food consumption in the WT rats. In contrast, Y5 antagonist at a dose of 30 , but not $10 \mathrm{mg} / \mathrm{BW}$ significantly decreased food consumption.

Effects of rhGH administration on TG rats: Changes in food consumption following rhGH or saline is shown in Fig. 6A. Food consumption in TG rats injected with saline was significantly larger than that in WT rats injected with saline throughout the experimental period. Treatment with rhGH significantly decreased food consumption of TG rats at days 5 and 6 . There was no difference in food consumption between WT rats with saline treatment and TG rats with rhGH treatment at day 6. Body weight, adipose tissue (CAO) weight and plasma triglyceride levels were significantly greater in TG than WT rats (Figs. 6B, C and D). Although treatment with rhGH for 7 days did not affect the body weight of TG rats, it significantly decreased adipose tissue weight and plasma triglyceride levels.

\section{DISCUSSION}

In the present study, the increase in body weight and food consumption was confirmed in female TG rats, which is 


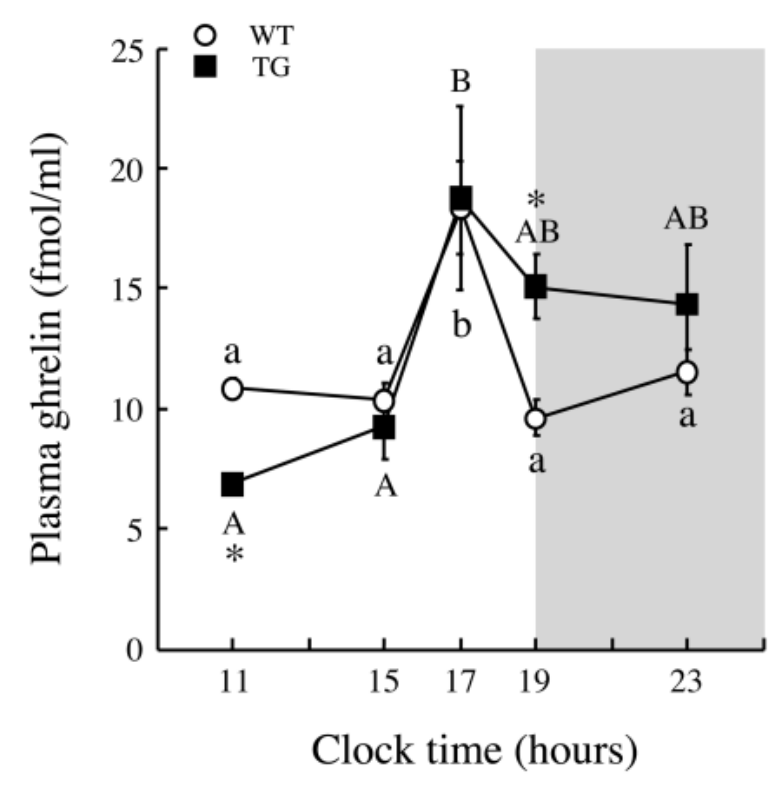

Fig. 3. Changes in plasma ghrelin concentrations in the wild-type (WT) and transgenic (TG) rats between 1100 and $2300 \mathrm{hr}$. Shaded area represents the dark phase. Each symbol and vertical bar represents mean $\pm \mathrm{SE}(\mathrm{n}=5-7){ }^{*} \mathrm{p}<0.05$ vs. WT. Values with different characters are significantly different $(\mathrm{p}<0.05)$.

consistent with our previous observations in male TG rats $[12,15]$. The largest food consumption was observed right after the beginning of the dark phase (1900-2100 hr), which followed the peak levels of plasma ghrelin just before the dark phase (1700 hr), in both the WT and TG rats. The peak levels of plasma ghrelin before the dark phase was also reported by Murakami et al. [26], which may be related to the increase in food intake at the beginning of the dark phase. Although there was no difference in the peak values of plasma ghrelin at $1700 \mathrm{hr}$ between the WT and TG rats, the level at $1900 \mathrm{hr}$ was significantly higher in the TG than WT rats. The level at $2300 \mathrm{hr}$ was also higher in the TG than WT rats, though not significantly. This increase in plasma ghrelin levels in the TG rats may account for hyperphagia during the dark phase in the TG rats.

The contents of NPY in both the ARC and PVN were also highest at $1700 \mathrm{hr}$, which was consistent with a previous report by Jhanwar-Uniyal et al. [21] who showed that there was a peak in NPY contents in both the ARC and the parvocellular subdivision of the PVN just before the dark phase. These peaks of hypothalamic NPY levels were probably due to the increase in plasma ghrelin levels at this time, since it is known that ghrelin can increase mRNA expression and peptide production of NPY [30,33]. Although the pattern of changes in NPY contents in the hypothalamic nuclei was similar between the WT and TG rats, the levels in the ARC were always higher in the WT than TG rats and those in the PVN at $1700 \mathrm{hr}$ were higher in the TG than WT rats. The precise reasons for these differences in NPY contents in the hypothalamus currently remain unclear. However, since we have observed in males that NPY mRNA expression in the ARC of the TG is not different from that of the WT (our unpublished observation), we speculate that the differences in NPY contents are not attributable to the difference in NPY synthesis, but to the difference in the excitability of NPY neurons that may stimulate the transport of NPY from the ARC to PVN and its release from the PVN.

In support of above assumption, antagonists for both the Y1 and Y5 receptors for NPY were much more effective in TG than WT rats. This suggests that hyperphagia observed in the TG rats largely depends on the NPY system in the hypothalamus. It has been shown that NPY stimulates food intake by acting on the NPY receptors expressed in neurons in the PVN [4]. In addition, it has been also demonstrated that the orexigenic action of ghrelin disappears by adminis-
A

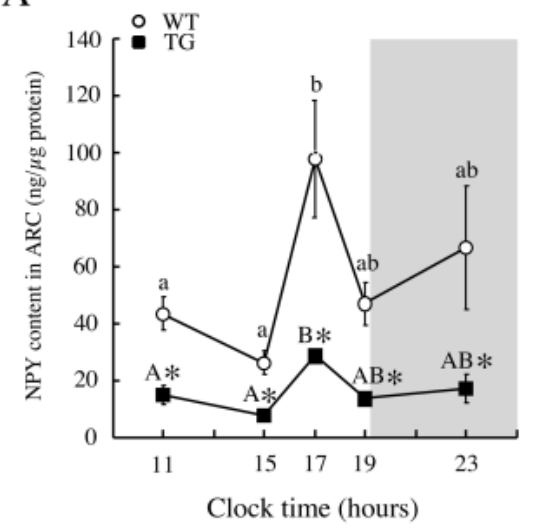

B

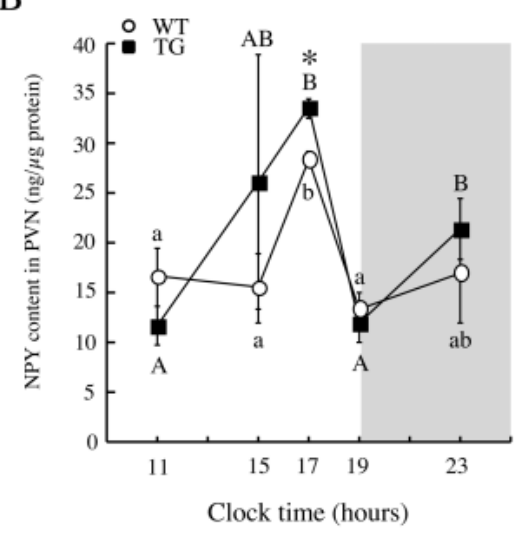

Fig. 4. Changes in NPY contents in the hypothalamic arcuate (ARC) (A) and paraventricular nuclei (PVN) (B) in the wild-type (WT) and transgenic (TG) rats between 1100 and $2300 \mathrm{hr}$. Shaded area represents the dark phase. Each symbol and vertical bar represents mean \pm SE $(n=4-6) .{ }^{*} \mathrm{p}<0.05$ vs. WT. Values with different characters are significantly different $(\mathrm{p}<0.05)$. 
A

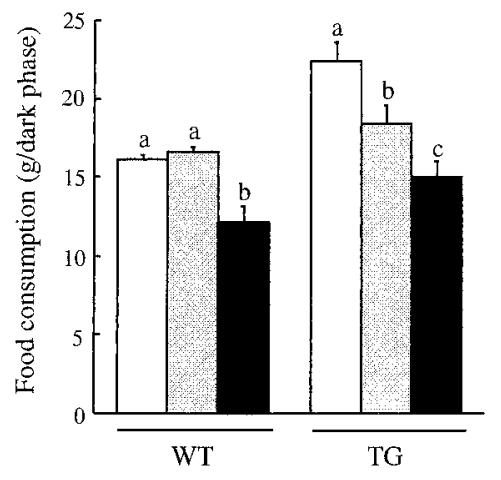

B

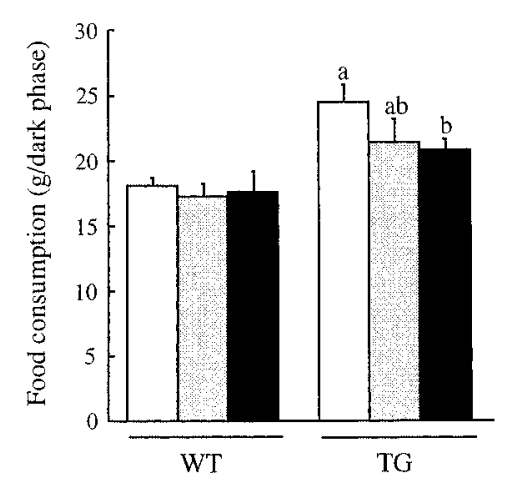

$\square$ vehicle

$10 \mathrm{mg} / \mathrm{body}$ weight

$30 \mathrm{mg} /$ body weight

Fig. 5. Effects of NPY Y1 (A) and Y5 (B) receptor antagonists on food consumption in the wild-type (WT) and transgenic (TG) rats. Animals were intraperitonealy administrated with vehicle, 10 and $30 \mathrm{mg} / \mathrm{kg}$ body weight of antagonists at $1800 \mathrm{hr}$, and the food consumption during the whole dark phase (1900-0700 hr) was measured. Each column and vertical bar represents mean $\pm \mathrm{SE}(\mathrm{n}=6)$. Values with different characters are significantly different $(\mathrm{p}<0.05)$.

A

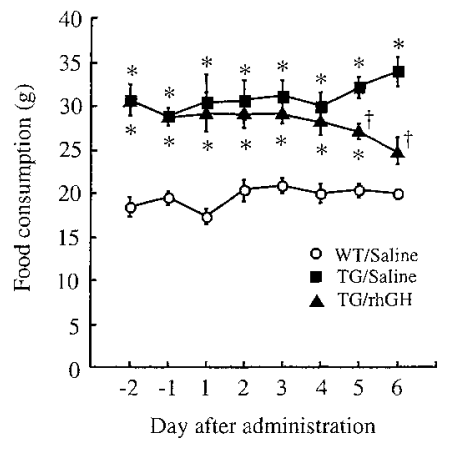

B

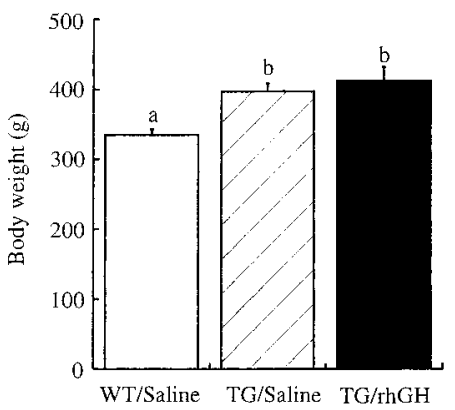

C

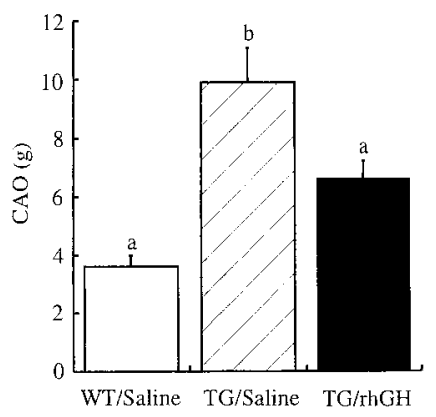

$\mathrm{D}$

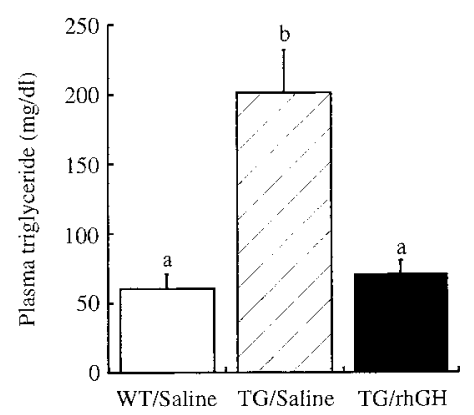

Fig. 6. Changes in daily food consumption (A), and resultant body weight (B), corpus adiposum ovarii (CAO) weight (C), and plasma triglyceride concentrations (D) following rhGH treatment. The wild-type (WT) and transgenic (TG) rats were treated with saline or rhGH at a dose of $100 \mu \mathrm{g} / \mathrm{rat} 4$ times a day at $4 \mathrm{hr}$ intervals between 0700 and $1900 \mathrm{hr}$ for 7 days. Each symbol, column and vertical bar represents mean \pm $\mathrm{SE}(\mathrm{n}=6-9) .{ }^{*} \mathrm{p}<0.05$ vs. WT/Saline. $\uparrow \mathrm{p}<0.05$ vs. TG/Saline. Values with different characters are significantly different $(\mathrm{p}<0.05)$. 
tration of $\mathrm{Y} 1$ or $\mathrm{Y} 5$ receptor antagonists [27]. Taken together, it is suggested that, in the TG rats, the excitability of NPY neurons in the ARC is facilitated during the dark phase at least partially by the increase in plasma ghrelin levels, and NPY released in the PVN in turn increases food intake through the $\mathrm{Y} 1$ and $\mathrm{Y} 5$ receptors.

In the present study, intermittent administration of rhGH decreased adipose tissue weight and plasma triglyceride levels in the TG rats, indicating that this treatment effectively caused lipolysis. This treatment also decreased food intake, suggesting that hyperphagia is caused at least partially by a decreased $\mathrm{GH}$ action in the TG rats. It has been shown that episodic administration of $\mathrm{GH}$ in rats decreased stomach ghrelin mRNA and plasma ghrelin levels [28], while hypophysectomy increased plasma ghrelin levels [31]. In human study, it is known that plasma ghrelin levels are high in PWS subjects who show GHD [14], whereas they are low in acromegalic subjects [5]. Therefore, although there are still some negative reports showing that GH treatment does not modify ghrelin secretion [20] and ghrelin levels are not influenced by GH levels in GHD subjects [25], endogenous GH appears to exert a negative feedback effect on stomach ghrelin production and secretion. If this is the case, intermittent treatment with rhGH may decrease plasma ghrelin levels, and thereby reduced food intake in the TG rats.

As discussed above, the present study suggests that the low circulating levels of GH are the primary cause for hyperphagia in the TG rats. At present, however, it is still difficult to simply correlate food intake with GH levels. For example, it has been reported that $\mathrm{GH}$ administration to intact rats increases food consumption [1], and that GH replacement increases NPY mRNA expression in the hypothalamus of hypophysectomized rats [6]. It may be noteworthy here to mention, however, that PWS subjects with GHD often develop eating disorders. Since there are several common features between PWS subjects and the TG rats used in the present study, including hyperphagia, obesity and gonadal dysfunction as well as GHD [3, 17, 32], dysfunction within GH-ghrelin-NPY system may also take part in eating disorders in PWS subjects. The TG rats could be used as good experimental model for the study of eating disorders and related metabolic diseases originating in inappropriate GH secretion like PWS.

ACKNOWLEDGMENTS. The authors thank Drs. Shuichi Koda and Mayumi Furuya, Daiichi Asubio Pharma Co., Ltd., for help in ghrelin assay.

\section{REFERENCES}

1. Azain, M. J., Roberts, T. J., Martin, R. J. and Kasser, T. R. 1995. Comparison of daily versus continuous administration of somatotropin on growth rate, feed intake, and body composition in intact female rats. J. Anim. Sci. 73: 1019-1029.

2. Bai, F. L., Yamano, M., Shiotani, Y., Emson, P. C., Smith, A. D., Powell, J. F. and Tohyama, M. 1985. An arcuato-paraventricular and -dorsomedial hypothalamic neuropeptide Y-containing system which lacks noradrenaline in the rat. Brain Res.
331: 172-175.

3. Burman, P., Ritzen, E. M. and Lindgren, A. C. 2001. Endocrine dysfunction in Prader-Willi syndrome: a review with special reference to GH. Endocr. Rev. 22: 787-799.

4. Campbell, R. E., ffrench-Mullen, J. M., Cowley, M. A., Smith, M. S. and Grove, K. L. 2001. Hypothalamic circuitry of neuropeptide $\mathrm{Y}$ regulation of neuroendocrine function and food intake via the Y5 receptor subtype. Neuroendocrinology 74: 106-119.

5. Cappiello, V., Ronchi, C., Morpurgo, P. S., Epaminonda, P., Arosio, M., Beck-Peccoz, P. and Spada, A. 2002. Circulating ghrelin levels in basal conditions and during glucose tolerance test in acromegalic patients. Eur. J. Endocrinol. 147: 189-194.

6. Chan, Y. Y., Steiner, R. A. and Clifton, D. K. 1996. Regulation of hypothalamic neuropeptide-Y neurons by growth hormone in the rat. Endocrinology 137: 1319-1325.

7. Criscione, L., Rigollier, P., Batzl-Hartmann, C., Rueger, H., Stricker-Krongrad, A., Wyss, P., Brunner, L., Whitebread, S., Yamaguchi, Y., Gerald, C., Heurich, R. O., Walker, M. W., Chiesi, M., Schilling, W., Hofbauer, K. G. and Levens, N. 1998. Food intake in free-feeding and energy-deprived lean rats is mediated by the neuropeptide Y 5 receptor. J. Clin. Invest. 102: 2136-2145.

8. Davidson, M. B. 1987. Effect of growth hormone on carbohydrate and lipid metabolism. Endocr. Rev. 8: 115-131.

9. Eden Engstrom, B., Burman, P., Holdstock, C. and Karlsson, F. A. 2003. Effects of growth hormone (GH) on ghrelin, leptin, and adiponectin in GH-deficient patients. J. Clin. Endocrinol. Metab. 88: 5193-51938.

10. Finkelstein, J. W., Roffwarg, H. P., Boyar, R. M., Kream, J. and Hellman, L. 1972. Age-related change in the twenty-fourhour spontaneous secretion of growth hormone. J. Clin. Endocrinol. Metab. 35: 665-670.

11. Furuhata, Y., Hirabayashi, K., Yonezawa, T., Takahashi, M. and Nishihara, M. 2002. Effects of pair-feeding and growth hormone treatment on obese transgenic rats. Eur. J. Endocrinol. 146: 245-249.

12. Furuhata, Y., Kagaya, R., Hirabayashi, K., Ikeda, A., Chang, K. T., Nishihara, M. and Takahashi, M. 2000. Development of obesity in transgenic rats with low circulating growth hormone levels: involvement of leptin resistance. Eur. J. Endocrinol. 143: 535-541.

13. Gehlert, D. R. 1999. Role of hypothalamic neuropeptide Y in feeding and obesity. Neuropeptides 33: 329-338.

14. Haqq, A. M., Farooqi, I. S., O'Rahilly, S., Stadler, D. D., Rosenfeld, R. G., Pratt, K. L., LaFranchi, S. H. and Purnell, J. Q. 2003. Serum ghrelin levels are inversely correlated with body mass index, age, and insulin concentrations in normal children and are markedly increased in Prader-Willi syndrome. J. Clin. Endocrinol. Metab. 88: 174-178.

15. Ikeda, A., Chang, K. T., Matsumoto, Y., Furuhata, Y., Nishihara, M., Sasaki, F. and Takahashi, M. 1998. Obesity and insulin resistance in human growth hormone transgenic rats. Endocrinology 139: 3057-3063.

16. Ikeda, A., Chang, K. T., Nakano, T., Matsuyama, S., Nishihara, M. and Takahashi, M. 1996. hGH transgenic rats expressing severe obesity and effect of treatment with hGH in a pulsatile manner. Endocr. J. 43 (Suppl.): S99-101.

17. Ikeda, A., Matsumoto, Y., Chang, K. T., Nakano, T., Matsuyama, S., Yamanouchi, K., Ohta, A., Nishihara, M., Tojo, H., Sasaki, F. and Takahashi, M. 1997. Different female reproductive phenotypes determined by human growth hormone (hGH) levels in hGH-transgenic rats. Biol. Reprod. 56: $847-$ 
851.

18. Ikeda, A., Matsuyama, S., Nishihara, M., Tojo, H. and Takahashi, M. 1994. Changes in endogenous growth hormone secretion and onset of puberty in transgenic rats expressing human growth hormone gene. Endocr. J. 41: 523-529.

19. Ishihara, A., Kanatani, A., Okada, M., Hidaka, M., Tanaka, T., Mashiko, S., Gomori, A., Kanno, T., Hata, M., Kanesaka, M., Tominaga, Y., Sato, N. A., Kobayashi, M., Murai, T., Watanabe, K., Ishii, Y., Fukuroda, T., Fukami, T. and Ihara, M. 2002. Blockade of body weight gain and plasma corticosterone levels in Zucker fatty rats using an orally active neuropeptide $\mathrm{Y}$ Y1 antagonist. Br. J. Pharmacol. 136: 341-346.

20. Janssen, J. A., van der Toorn, F. M., Hofland, L. J., van Koetsveld, P., Broglio, F., G-higo, E., Lamberts, S. W. and Jan van der Lely, A. 2001. Systemic ghrelin levels in subjects with growth hormone deficiency are not modified by one year of growth hormone replacement therapy. Eur. J. Endocrinol. 145: 711-716.

21. Jhanwar-Uniyal, M., Beck, B., Burlet, C. and Leibowitz, S. F. 1990. Diurnal rhythm of neuropeptide Y-like immunoreactivity in the suprachiasmatic, arcuate and paraventricular nuclei and other hypothalamic sites. Brain Res. 536: 331-344.

22. Kanatani, A., Hata, M., Mashiko, S., Ishihara, A., Okamoto, O., Haga, Y., Ohe, T., Kanno, T., Murai, N., Ishii, Y., Fukuroda, T., Fukami, T. and Ihara, M. 2001. A typical Y1 receptor regulates feeding behaviors: effects of a potent and selective Y1 antagonist, J-115814. Mol. Pharmacol. 59: 501-505.

23. Kanatani, A., Ishihara, A., Iwaasa, H., Nakamura, K., Okamoto, O., Hidaka, M., Ito, J., Fukuroda, T., MacNeil, D. J., Van der Ploeg, L. H., Ishii, Y., Okabe, T., Fukami, T. and Ihara, M. 2000. L-152,804: orally active and selective neuropeptide Y Y5 receptor antagonist. Biochem. Biophys. Res. Commun. 272: 169-173.

24. Kojima, M., Hosoda, H., Date, Y., Nakazato, M., Matsuo, H. and Kangawa, K. 1999. Ghrelin is a growth-hormone-releasing acylated peptide from stomach. Nature (Lond.) 402: 656-660.

25. Malik, I. A., English, P. J., Ghatei, M. A., Bloom, S. R., Mac-
Farlane, I. A. and Wilding, J. P. 2004. The relationship of ghrelin to biochemical and anthropometric markers of adult growth hormone deficiency. Clin. Endocrinol. (Oxf.) 60: 137-141.

26. Murakami, N., Hayashida, T., Kuroiwa, T., Nakahara, K., Ida, T., Mondal, M. S., Nakazato, M., Kojima, M. and Kangawa, K. 2002. Role for central ghrelin in food intake and secretion profile of stomach ghrelin in rats. J. Endocrinol. 174: 283-288.

27. Nakazato, M., Murakami, N., Date, Y., Kojima, M., Matsuo, H., Kangawa, K. and Matsukura, S. 2001. A role for ghrelin in the central regulation of feeding. Nature (Lond.) 409: 194-198.

28. Qi, X., Reed, J., Englander, E. W., Chandrashekar, V., Bartke, A. and Greeley, G. H., Jr. 2003. Evidence that growth hormone exerts a feedback effect on stomach ghrelin production and secretion. Exp. Biol. Med. (Maywood) 228: 1028-1032.

29. Salomon, F., Cuneo, R. C., Hesp, R. and Sonksen, P. H. 1989. The effects of treatment with recombinant human growth hormone on body composition and metabolism in adults with growth hormone deficiency. New Engl. J. Med. 321: 17971803.

30. Shintani, M., Ogawa, Y., Ebihara, K., Aizawa-Abe, M., Miyanaga, F., Takaya, K., Hayashi, T., Inoue, G., Hosoda, K., Kojima, M., Kangawa, K. and Nakao, K. 2001. Ghrelin, an endogenous growth hormone secretagogue, is a novel orexigenic peptide that antagonizes leptin action through the activation of hypothalamic neuropeptide $\mathrm{Y} / \mathrm{Y} 1$ receptor pathway. Diabetes 50: 227-232.

31. Tschop, M., Flora, D. B., Mayer, J. P. and Heiman, M. L. 2002. Hypophysectomy prevents ghrelin-induced adiposity and increases gastric ghrelin secretion in rats. Obes. Res. 10: 991999.

32. Wattendorf, D. J. and Muenke, M. 2005. Prader-Willi syndrome. Am. Fam. Physician. 72: 827-830.

33. Wren, A. M., Small, C. J., Fribbens, C. V., Neary, N. M., Ward, H. L., Seal, L. J., Ghatei, M. A. and Bloom, S. R. 2002. The hypothalamic mechanisms of the hypophysiotropic action of ghrelin. Neuroendocrinology 76: 316-324. 